\title{
Effect of the concept education programme on 48-60-month-old children's visual-spatial perception mechanisms
}

\begin{tabular}{|c|c|}
\hline \multicolumn{2}{|c|}{$\begin{array}{l}\text { Authors: } \\
\text { Miray Ö. Danacli } \bullet \\
\text { Zeynep Çetin }{ }^{2}\end{array}$} \\
\hline \multicolumn{2}{|c|}{$\begin{array}{l}\text { Affiliations: } \\
{ }^{1} \text { Department of Early } \\
\text { Childhood Education, Faculty } \\
\text { of Education, Izmir Demokrasi } \\
\text { Üniversitesi, Izmir, Turkey }\end{array}$} \\
\hline \multicolumn{2}{|c|}{$\begin{array}{l}{ }^{2} \text { Department of Child } \\
\text { Development, Faculty of } \\
\text { Health, Hacettepe University, } \\
\text { Ankara, Turkey }\end{array}$} \\
\hline \multicolumn{2}{|c|}{$\begin{array}{l}\text { Corresponding author: } \\
\text { Miray Danacı, } \\
\text { mirayozozen@hotmail.com }\end{array}$} \\
\hline \multicolumn{2}{|c|}{$\begin{array}{l}\text { Dates: } \\
\text { Received: } 05 \text { Oct. } 2020 \\
\text { Accepted: } 23 \text { Oct. } 2021 \\
\text { Published: } 31 \text { Jan. } 2022\end{array}$} \\
\hline \multicolumn{2}{|c|}{$\begin{array}{l}\text { How to cite this article: } \\
\text { Danacl, M.O. \& Çetin, Z., } \\
2022, \text { 'Effect of the concept } \\
\text { education programme on } \\
48-60 \text {-month-old children's } \\
\text { visual-spatial perception } \\
\text { mechanisms', South African } \\
\text { Journal of Childhood } \\
\text { Education } 12(1) \text {, a942. } \\
\text { https://doi.org/10.4102/ } \\
\text { sajce.v12i1.942 }\end{array}$} \\
\hline \multicolumn{2}{|c|}{$\begin{array}{l}\text { Copyright: } \\
\text { (C) 2022. The Authors } \\
\text { Licensee: AOSIS. This } \\
\text { is licensed under the } \\
\text { Creative Commons } \\
\text { Attribution License. }\end{array}$} \\
\hline \multicolumn{2}{|l|}{ Read online: } \\
\hline 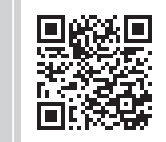 & $\begin{array}{l}\text { Scan this QR } \\
\text { code with your } \\
\text { smart phone or } \\
\text { mobile device } \\
\text { to read online. }\end{array}$ \\
\hline
\end{tabular}

Background: To understand how the human brain organises the information, how prototypes are handled in the categorisation system, researchers have pointed out that there may be a relationship between visual perception and concept acquisition.

Aim: This study was conducted to examine the effect of a concept education programme, developed on the basis of a configured concept map, on the visual-spatial perception mechanisms of children between the ages of 48 and 60 months who were selected through random sampling from central kindergartens.

Setting: The experimental group and control group each included 59 children. For data collection, the Frostig developmental test of visual perception and the Boehm Test of Basic Preschool Concepts-3 were used.

Methods: The experimental group and control group each included 59 children. For data collection, the Frostig developmental test of visual perception and the Boehm Test of Basic Preschool Concepts-3 were used.Additionally, the concept education programme based on configured concept map was developed by consulting expert opinions, and this programme was applied to the experimental group.

Results: In assessing the relationship between pre- and post-test scores, the findings indicate that a significant increase occurred in favour of the post-test results. However, a significant relationship favouring the experimental group was present between the post-test scores of experimental and control groups. No significant difference was found between the post-test/ monitoring measurements regarding visual-spatial perception and Boehm-3 concept skills. The data suggest that the concept education programme supported the development of children's visual perception skills.

Conclusion: On the basis of the study results, parents, teachers and researchers are recommended to use concept maps in the learning processes, particularly those related to visual-spatial perception.

Keywords: early childhood; visual perception; education on concept; concept map; perception skills.

\section{Introduction}

The period of early childhood, which covers the time from a child's birth to their primary school years, plays a significant role in shaping the life of children. Physical, psychomotor, language, social or emotional and cognitive developments take place more rapidly than at any other time in life during this period. Therefore, it is important that at this time, children gain new experiences and have their developmental areas supported to ensure that they have a successful life (Frank \& Barner 2012; Genc 2003).

Cognitive development involves the use of certain skills, such as mental perception, retention, reasoning, decision-making and problem solving. Moreover, visual perception is also quite important for cognitive development, especially considering that $98 \%$ of what babies learn during the first year of their lives relies on visual perceptions. Visual perception is the most effective and strongest sense among the other perception types (Erden \& Akman 2005). Qualitative and quantitative characteristics of the object or stimulant, such as colour, dimension, light, form, shape, volume, pattern, location, direction or function, are important

Note: This article was given to Hacettepe University, Department of Child Development in 2017 produced from the doctoral thesis of Miray Özözen Danacı under the supervision of Zeynep Çetin. 
regarding visual-spatial perception (Cukur \& GullerDelice 2011). Researchers suggest that sensitivity related to visual-spatial perception increases at the age of 4 or 5 and continues to increase until the age of 7 . Thus, during the early childhood period, it is important that children focus on visual information by using concepts examine the details of the pictures and objects and understand how these elements are related to the whole (Erisli, Uluuysal \& Dindar 2013; Healey 1997).

Concepts make the learning process effective by assisting people in separating their worlds into small parts. The learning process is more effective because of concept formation during which humans separate their worlds into smaller units. Children use their sense organs to obtain information from these parts (Manocha \& Narang 2004).

The visual world has both visible elements, such as distance, height, depth, permanence, colour, shade, luminosity, tactility and shapeliness, and invisible elements, such as independence and hidden mathematical equations, rules and formulas (Erden \& Akman 2005). These hidden elements can be processed using a structure that includes concept acquisition and concept learning (Wallace \& Mintzes 1990).

One of the ways for developing visual-spatial perception during the preschool period is to use child-centred educational methods, among which include the concept map method, a widely used application in concept education (Wallace \& Mintzes 1990). Novak's concept map (Novak 1998), suggests that concepts are ordered in a sequence that runs from particular to general, with the most general concept at the top and the most particular concept at the bottom, to form what is seen as a hierarchical structure in people's minds (Karaahmet-Balc1 2015). Concept education helps children to form a relationship between the knowledge they obtain from pre-learning and the acquisition of new knowledge (Eddie \& Gray 2007).

Concept maps are very effective learning methods in terms of organising information, categorising information, making it concrete and productive, making sense of information and establishing links between concepts (Novak 1990).

Therefore, concept maps have been preferred in this research for developing visual perception because it ensures and establishes the visual links and relationships between concepts with and observable illustrations.

Based on the research and the literature focused on conceptual studies, this study introduces and depends on the statement: 'The natural cognitive capacity of a person is effective for acquiring a concept, but this capacity develops with experience, in other words with training provided'. The acquisition of concepts and learning skills is directly proportional to the acquisition of certain intellectual skills. Taking this statement as a premise, this study aimed to determine whether or not education based on a concept map that was provided to children ranging in age between 48 and 60 months who attended kindergarten is effective in their visual-spatial perception development.

\section{Methods Study design}

The experimental model was used in this study examining the effectiveness of a concept education programme on visual-spatial perception mechanisms.

The application process consisted of three stages:

1. Preparations were conducted, experimental and control groups were formed and measurement tools were applied on both groups.

2. The programme was administered to the experimental group for 8 months after the preparations for the relevant curricula were completed.

3. Both evaluation tools were re-administered to the experimental and control groups and a monitoring test was performed after 2 weeks.

\section{Population and sample}

The inclusion criteria used to form the groups were the participants had a normal development process, equal family structure, equal duration of preschool education, no experience of attending a concept education programme and or visual perception programme, similar maternal and paternal educational status, and spoke Turkish as their mother language. Children's history regarding any neurological or psychiatric condition was determined with special education experts.

\section{Sample}

The sample consisted of 118 children (59 children in each group) who were enrolled in different kindergartens operating under the Turkish Ministry of National Education (MEB) in Duzce, a province in northwestern Turkey. Their ages ranged between 48 and 60 months.

During the sample generation stage, a list including all the kindergartens which host children between the ages of 48 and 60 months was obtained from the Duzce Provincial Directorate for National Education. The children were selected from different schools and divided into experimental and control groups using the random sampling method. The experimental group consisted of two classes, with the first class including 48-month-old children and the second class including 60-month-old children.

A total of 118 children constituted the sample, from which an equal amount of children were assigned to experimental and control groups. Of the children in the experimental group, $28.3 \%$ were $48-53$ months old, and $21.7 \%$ were 54-60 months old, while of the children in the control 
group, 30.8\% were 48-53 months old, and 19.1\% were 54-60 months old.

Both groups consisted of an equal number of women and men. Regarding duration of preschool education, 1.6\% received preschool education for a period shorter than 3 months, $34.7 \%$ for $3-6$ months, $8.4 \%$ for a period of between 6 months and 1 year, 3.3\% for a period of between 1 and 2 years and $1.6 \%$ for more than 2 years.

In terms of the siblings in the experimental group, $15.2 \%$ of the children had no siblings, $38.9 \%$ had one sibling, $23.7 \%$ had two siblings, $11.8 \%$ had three siblings, $6.7 \%$ had four siblings and $3.3 \%$ had five or more siblings. A majority of the children in this group had one sibling.

In terms of the siblings in the control group, $8.4 \%$ had no siblings, $32.2 \%$ had one sibling, $35.5 \%$ had two siblings, $8.4 \%$ had three siblings, $10.1 \%$ had four siblings and $5.0 \%$ had five or more siblings.

\section{Data collection tools}

For data collection, this study used the 'Personal Information Form', developed by the researchers, Frostig's Lefever and Whittlesey (1961), 'Frostig Developmental Test of Visual Perception' and Boehm's (2001) 'Boehm Test of Basic Preschool Concepts-3'.

\section{Personal information form}

The personal information form, which was prepared by the researchers to obtain data regarding the participating children and their families, included questions addressing the children's chronological age, gender, maternal and paternal educational status, number of siblings, socioeconomic and cultural levels and period of education.

\section{Frostig developmental test of visual perception}

The Frostig developmental test of visual perception is a visualspatial perception measurement tool that can be administered to children in the early childhood period and in first grade.

The test was developed by Marianne Frostig in (1961) following studies that had been conducted with children experiencing learning disabilities. The validity and reliability study was conducted by Frostig, Lefever and Whittlesey (Frostig et al. 1961). Sokmen (1994) is credited for adapting it for use in Turkey. The test-retest method was used to determine the stability coefficient, which was calculated to be 0.01. Calculations for the internal consistency correlation coefficient between the general test and sub-dimensions indicate that the sub-dimensions and the test had an internal consistency of 0.05 . Results obtained from the item analysis show that the test resembles the original one, and thus, is reliable.

The test is administered to children who are between the ages of 4.0 and 7.11, and it has five subtests (Sagol 1998):
1. visual-motor coordination

2. figure-ground perception

3. stability of the figure

4. perception of the place and location

5. perception of the spatial relationships.

Since its inception, the Frostig developmental test of visual perception is a test that has been used most frequently in the studies involving the evaluation of visual perception skills.

\section{Boehm Test of Basic Preschool Concepts-3}

The Boehm Test of Basic Concepts was developed as an educational screening test to determine children's skills regarding basic concepts during early childhood, to identify children's deficiencies in acquiring concepts to reduce the number of these deficiencies and to assess their curricula (Boehm 2001).

The test was developed by Ann E. Boehm in 1986 and revised in the same year to become Boehm-R. The Boehm Test of Basic Preschool Concepts-3 version was developed in 2001.

The validity and reliability of the Boehm Test of Basic Concepts was examined by Sucuoglu, Buyukozturk and Ozenmis (2007) and Ergul (2007), all who used different methods, and as part of these studies, the current validity and predictive validity were examined. Boisvert (2003) conducted the validity and reliability study for the haptic version of the test. Moreover, Boehm (2001) calculated split half reliability, which was found to be 0.90 and 0.82 , as well as Kuder-Richardson coefficient and the standard error. The KR-20 reliability value was 0.79 for the whole group and ranged between 0.58 and 0.84 in the subgroups.

The Pearson's correlation coefficient between the scores obtained using test-retest method was $r=0.782(p=0.01)$. The internal consistency coefficient, which indicates whether or not the items in the scale are homogeneous, was 94 at $0.8<$ Alpha $<1.0$ (Boisvert 2003).

\section{Generating the concept map}

Concept Maps were prepared in accordance to the purpose of the study. The aim was that concept maps include the process by which the network, rules, typography, relevant-irrelevant characteristics, elements and the taxonomy are taught and evaluated through the drawing and interpretation of a perceptual framework.

When generating the formal dimension of the concept maps, the following were considered:

- concepts

- hierarchy

- cross correlations

- examples

- connection arrows

- visuality

- authenticity. 


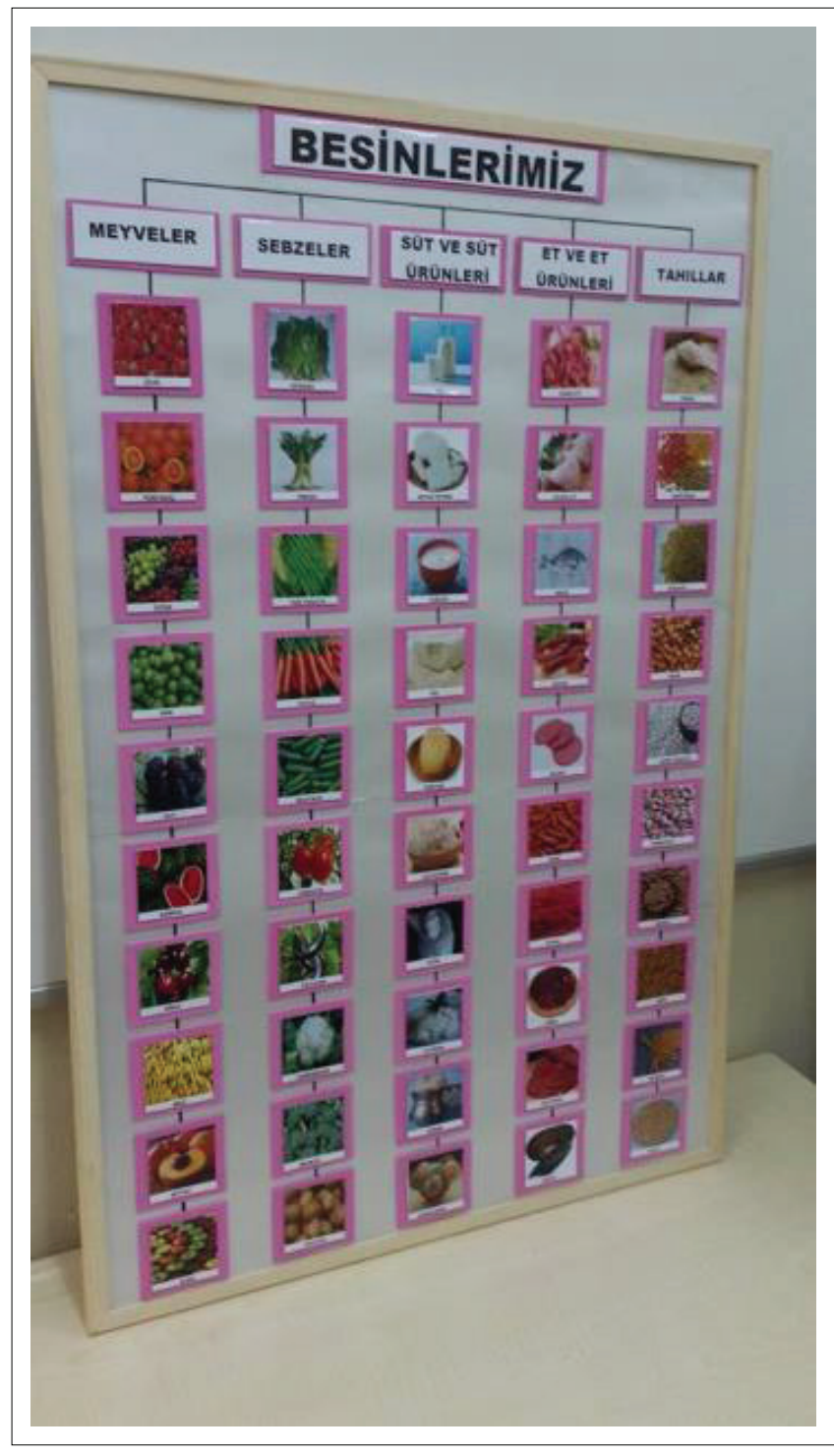

FIGURE 1: An example concept map. (1) Nutrients. (a) Fruits. (b) Vegetables. (c) Milk and milk products. (d) Meat and meat products. (e) Cereals.

Concept maps (see Figure 1) were ordered from the simple to the complicated. Eight concept maps related to items of food, clothes, animals, getting to know their bodies, professions, vehicles and sky were generated and separated into hierarchies in accordance to certain characteristics suitable to children's perceptions.

When preparing the content details of the concept maps, the following were considered:

- flexibility (e.g. adding fruits such as 'raspberry, mango, pineapple', which were not originally on the map, to facilitate activity flow)

- suitability to the culture (e.g. including dried curd, which is a staple product of the Duzce region, under the dairy products items)

- distinctiveness (e.g. not including cherry and sour cherry, and garden rocket and cress in the same category, because they have different qualitative characteristics).

The concept maps to be examined as part of the educational programmes related to concepts were separated into sub-categories, and starting from the upper hierarchy, the original picture of the concept was provided in a box in each sub-category, with the name of the concept being provided above.

\section{Educational programme based on concept map}

After generating the concept maps, the experimental group was trained 3 days a week for 8 weeks on the hierarchy and categories. After learning the names of all entities, the aim was to consolidate the concepts using the concepts related to each entity.

During each educational session, children were shown the effectiveness of the concept maps by engaging in activities that include the concepts of MEB's preschool curricula. The activities were performed as questions and answers, which served to support their imagination, interest and curiosity. Concept maps were presented after the activities, with the concepts in the map being provided.

The educational programme applied to the experimental group was prepared and implemented as follows.

\section{Preparation}

1. The literature related to concept development skills of children was reviewed to prepare the educational programme.

2. Turkish Ministry of National Education's concept education programme based on configured concept map (CEPBCM) was prepared in accordance to the acquisitions and indicators in preschool curricula. The children's personal differences and developmental characteristics were considered while preparing the programme.

3. Experts were consulted for their opinions on the CEPBCM programme, which was implemented on the experimental group for an 8-week period. Statistical results indicated that the consistency value between the opinions of the seven experts consulted was 0.94 .

\section{Implementation}

1. The study involved 24 activities and consisted of 45-60min sessions, 3 days a week for 8 weeks, with the focus being on the hierarchy and categories of the concepts.

2. Concept map education was completed with different activities implemented in the first stage of each schoolday.

3. The objective was that the children obtain preexperiences with the activities related to the entities. The concepts in the hierarchy that were related to that day were separately marked using question-answer method. Similarities and differences were indicated in the explanation to each entity. After the entities were explained, relevant sentences were formed, and the usage details regarding the entities were developed.

4. Concept education studies supporting concept map education programme based on configured concept map, which was implemented on the experimental group, were prepared considering the activities in the CEPBCM. 

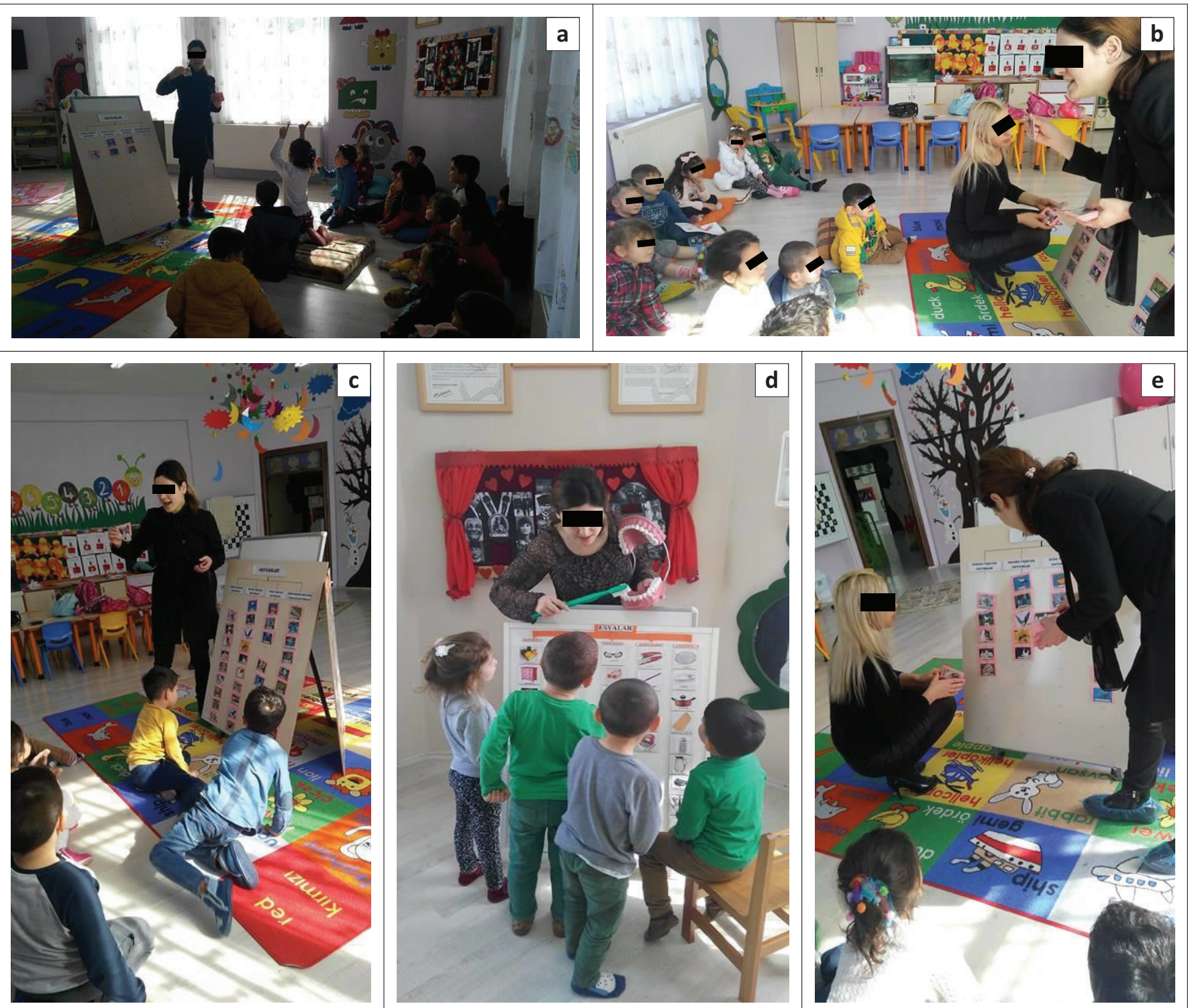

Source: Photographs from the Implementation Stages of the Educational Program

FIGURE 2: Sections from the implementation stage (a-e) of concept education programme based on configured concept map programme.

\section{Data collection}

Relevant literature was reviewed and necessary details were revised prior to obtaining data. Evaluation tools were used and educational practices were performed after the researcher obtained the necessary permission. The kindergartens operating under the Ministry of National Education in Duzce were determined for the experimental study, and the following methods were used for data collection (see Figure 2):

1. Validity and reliability studies of Boehm-3 test were conducted, and the relevant details were provided.

2. Frostig Developmental Test of Visual Perception (FDTVP) and Boehm-3 tests were implemented as pre-test to the children in the experimental and control groups that constituted the study group. Questions were directed at each child to see if they understood the test before its implementation. Errors the children made were not corrected, and they were not told about these errors.

3. Educational programme based on concept map was implemented with the children in the experimental group for 8 weeks. This programme was not implemented with the children in the control group.

4. Following the implementation of the educational programme in the experimental group, FDTVP and Boehm-3 tests were re-administered as post-test to the children in the experimental group.

5. After completion of the 8-week educational programme, Boehm-3 and FDTVP tests were administered as monitoring tests on 59 children 2 weeks later, and the data were statistically analysed.

\section{Data analysis}

Children's visual-spatial perceptions and conceptual skills were evaluated using FDTVP and Boehm-3 tests, respectively. The following methods were used for the analysis of the data. The scores each child obtained on the Boehm-3 and FDTVP tests and their sub-dimensions were separately calculated. No difference was found between the groups in terms of the 
mean scores obtained by the children in the pre- and postapplication stage.

\section{Findings}

This section presents the data analysis findings related to the variables related to the children of the study group before and after undergoing the concept education.

The values in Table 1 indicate that a significant difference was present between the visual-spatial perception skills post-test results of the experimental and control groups $(t(92)=-6.79 ; p<0.05)$. Post-test scores for the visual-spatial perception of the experimental group $(\bar{X}=97.91)$, on which the CEPBCM programme was implemented, were found to be significantly higher than those of the control group $(\bar{X}=76.21)(p<0.05)$.

The data in Table 1 indicate that on the Boehm test, there was a significant difference between the conceptual skills posttest results achieved by the children in the two groups $(t(46)=-3.42 ; p<0.05)$. Results show that the conceptual skills post-test scores of the experimental group $(\bar{X}=158.40)$, which was educated using the concept map, were higher than those of the control group $(\bar{X}=134.51)$.

Results from Table 2 reveal that there was a significant difference between the pre- and post-test scores obtained on

TABLE 1: Paired $t$-test results regarding the Frostig Developmental Test of Visual Perception and Boehm-3 pre- and post-test scores for the independent groups of experimental and control groups.

\begin{tabular}{lcccccc}
\hline Group & $\boldsymbol{N}$ & $\overline{\boldsymbol{X}}$ & $\boldsymbol{S}$ & s.d. & $\boldsymbol{T}$ & $\boldsymbol{p}$ \\
\hline Pre-test & & & & & & \\
Experimental & 59 & 75.74 & 1.71 & 92 & 0.93 & 0.34 \\
Control & 59 & 74.11 & 2.87 & 92 & & \\
Post-test & & & & & & \\
Experimental & 59 & 97.91 & 4.76 & 92 & -6.79 & $0.00^{*}$ \\
Control & 59 & 76.21 & 1.03 & 92 & & \\
Pre-test & & & & & & \\
Experimental & 59 & 128.03 & 18.43 & 92 & 0.24 & 0.82 \\
Control & 59 & 131.75 & 16.20 & 92 & & \\
Post-test & & & & & & \\
Experimental & 59 & 158.40 & 11.07 & 46 & -3.42 & $0.00^{*}$ \\
Control & 59 & 134.51 & 17.65 & 46 & & \\
\hline s.d. standard & 59 & & & & &
\end{tabular}

s.d., standard deviation.

$*, p<0.05$. the 'Perception of the place and location', 'Visual-motor coordination', 'Figure-ground perception', 'Figure stability' and 'Perception of the spatial relationships' sub-dimensions $(T[30]=-8.54,-9.34,-7.64,-7.23,-4.51, p<0.05)$. The children's pre- and post-education 'Visual-motor' subtest scores were $\bar{X}=76.45$ and $\bar{X}=96.31$, respectively. Their pre-test score on the 'Figure-ground perception' subtest was $\bar{X}=75.59$ before the education, rising to $\bar{X}=97.73$ after the education. The 'Figure stability' subtest score rose from $\bar{X}=77.56$ to $\bar{X}=99.89$; the 'Perception of the place and location' subtest score rose from $\bar{X}=73.82$ to $\bar{X}=98.43$ and the 'Spatial relationships' subtest score rose from $\bar{X}=75.01$ to $\bar{X}=96.40$.

Table 3 indicates that there was a significant difference between the Boehm-3 scores obtained by the experimental group on 'Visual-motor coordination', 'Figure-ground

TABLE 3: The relationship between the sub-dimensions of FDTVP and Boehm-3 test.

\begin{tabular}{|c|c|c|c|c|c|}
\hline Sub-dimensions & $\begin{array}{l}\text { Sum of } \\
\text { squares }\end{array}$ & s.d. & $\begin{array}{l}\text { Mean } \\
\text { square }\end{array}$ & $\boldsymbol{F}$ & $p$ \\
\hline \multicolumn{6}{|c|}{ 1. Visual-motor coordination (GMC) } \\
\hline Intergroup & 2.32 & 5 & - & 2.65 & $0.032 *$ \\
\hline Intragroup & 68.34 & 117 & 0.218 & & \\
\hline Total & 70.66 & 122 & - & & \\
\hline \multicolumn{6}{|c|}{ 2. Figure-ground perception (FGP) } \\
\hline Intergroup & 2.76 & 5 & - & 3.56 & $0.040^{*}$ \\
\hline Intragroup & 77.41 & 117 & 0.232 & & \\
\hline Total & 80.17 & 122 & - & & \\
\hline \multicolumn{6}{|c|}{ 3. Figure stability (FS) } \\
\hline Intergroup & 2.87 & 5 & - & 2.45 & $0.030^{*}$ \\
\hline Intragroup & 81.66 & 117 & 0.246 & & \\
\hline Total & 84.53 & 122 & - & & \\
\hline \multicolumn{6}{|c|}{ 4. Perception of the place and location (PPL) } \\
\hline Intergroup & 2.65 & 5 & - & 2.95 & $0.038^{*}$ \\
\hline Intragroup & 76.45 & 117 & 2.74 & & \\
\hline Total & 79.10 & 122 & - & & \\
\hline \multicolumn{6}{|c|}{ 5. Perception of the spatial relationships (PSR) } \\
\hline Intergroup & 2.33 & 5 & - & 3.073 & $0.041^{*}$ \\
\hline Intragroup & 79.82 & 117 & 2.91 & & \\
\hline Total & 82.15 & 122 & - & & \\
\hline \multicolumn{6}{|c|}{ General mean values of FDTVP } \\
\hline Intergroup & 0.78 & 5 & - & 2.871 & $0.043^{*}$ \\
\hline Intragroup & 76.67 & 117 & - & & \\
\hline Total & 77.45 & 122 & - & & \\
\hline
\end{tabular}

s.d., standard deviation; FDTVP., Frostig Developmental Test of Visual Perception. $*, p<0.05$.

TABLE 2: Paired sample $t$-test results regarding the pre- and post-test scores obtained by the experimental group on the FDTVP.

\begin{tabular}{|c|c|c|c|c|c|c|c|c|}
\hline Sub-dimensions & Tests & $N$ & $\overline{\bar{X}}$ & $S$ & s.d. & $t$ & $p$ & $D$ \\
\hline \multirow[t]{2}{*}{ Visual motor } & Pre-test & 59 & 76.45 & 7.86 & 30 & -9.34 & $0.000^{*}$ & 1.21 \\
\hline & Post-test & 59 & 96.31 & 8.45 & & & & \\
\hline \multirow[t]{2}{*}{ Figure-ground } & Pre-test & 59 & 75.59 & 8.67 & 30 & -7.64 & $0.001^{*}$ & 1.88 \\
\hline & Post-test & 59 & 97.73 & 9.34 & & & & \\
\hline \multirow[t]{2}{*}{ Stability of the figure } & Pre-test & 59 & 77.56 & 10.1 & 30 & -7.23 & $0.000^{*}$ & 78 \\
\hline & Post-test & 59 & 99.89 & 11.58 & & & & \\
\hline \multirow[t]{2}{*}{ Place and location } & Pre-test & 59 & 73.82 & 6.78 & 30 & -8.54 & $0.014^{*}$ & 2.91 \\
\hline & Post-test & 59 & 98.43 & 8.44 & & & & \\
\hline \multirow[t]{2}{*}{ Spatial relationships } & Pre-test & 59 & 75.01 & 7.53 & 30 & -4.51 & $0.035^{*}$ & -1.34 \\
\hline & Post-test & 59 & 96.40 & 7.98 & & & & \\
\hline
\end{tabular}

s.d., standard deviation.

$*, p<0.05$. 
TABLE 4: Results regarding the comparison of the correlation values between experimental group's visual perception scores from FDTVP test and conceptual skill scores (post-test) from Boehm-3 test.

\begin{tabular}{lcc}
\hline Tests & Visual perception & Concept skills \\
\hline Visual perception score & 1.000 & \\
$r$ & 0.00 & 0.561 \\
$p$ & 120 & 0.00 \\
$n$ & & 120 \\
Boehm-3 concept score & 0.561 & \\
$R$ & 0.00 & 1000 \\
$p$ & 120 & 0.00 \\
$n$ & & 120 \\
\hline
\end{tabular}

TABLE 5: Wilcoxon's signed-rank test results regarding the mean post-test scores obtained by the experimental group on the Boehm-3, FDTVP and monitoring (permanence) tests.

\begin{tabular}{lcccccccc}
\hline Tests & $\boldsymbol{N}$ & $\overline{\boldsymbol{X}}$ & Mean & Min. & Max. & s.d. & Wilcoxon & $\boldsymbol{p}$ \\
\hline Boehm-3 & & & & & & & & \\
Post-test & 59 & 158.0 & 142.09 & 122.79 & 161.39 & 4.0 & -0.254 & 0.875 \\
Permanence & 59 & 16071 & - & 11953 & 16048 & 40 & & \\
FDTVP & & & & & & & & \\
Post-test & 59 & 8691 & 86105 & 77.41 & 94.80 & 3.2 & -0.351 & 0.604 \\
Permanence & 59 & 87.65 & - & 78.18 & 96.23 & 3.2 & & \\
\hline
\end{tabular}

s.d., standard deviation; FDTVP, Frostig Developmental Test of Visual Perception. $p>0.05$.

perception', 'Figure stability', 'Perception of the place and location' and 'Perception of the spatial relationships' dimensions. A positive, significant relationship was present between all FDTVP sub-dimensions and the children's conceptual skills $(p<0.05)$.

The findings in Table 4 indicate that there was a strong, significant correlation in children's scores obtained on the FDTVP and Boehm-3 tests $(r=0.561 . p=0.000)$. Otherwise stated, the children's visual-spatial perception skills improved as their conceptual skills scores increased.

Table 5 indicates that the scores the experimental group obtained on the Boehm-3 and FDTVP test monitoring (permanence) did not differ from the scores obtained on the post-tests, and that the mean scores were similar to one another $(p>0.05)$. A detailed examination of the table shows that there were no significant differences between the post-test score on the visual perception and conceptual skills in the permanence test performed 2 weeks after the post-test, and that the permanence (monitoring) test scores were slightly higher than the post-test scores. This indicates that the experimental groups' scores on the Boehm-3 and FDTVP tests increased in 2 weeks, and that the effects of the education became clearer and more permanent over time.

\section{Discussion}

\section{Main findings}

This study has shown that the Concept Education Program Based on Configured Concept Map, which was generated from concept functions regarded as important mental activities and functioned to revise the details, positively affected children's visual-spatial perception mechanisms. Experimental and control groups were tested to see whether or not there was a difference in terms of the perceptual skills after the former received the Concept Education Program Based on Configured Concept Map. The children's pre- and post-education scores on the FDTVP and Boehm-3 tests, which are displayed in Table 1, indicated no significant difference between experimental and control groups.

As it seems post-test data in Table 1, it is fair to assume that the CEPBCM programme provided to the children is effective in terms of improving their visual-spatial perceptual skills, and that this education would yield more successful results in developing visual-perceptual skills compared to the traditional approach. Moreover, the concept maps significantly supported the learning process involving the characterisation of the entities and their separation into categories and thereby ensured their effectiveness. Thus, this study suggests that visual stimulants can be effective in developing visual-spatial perception mechanisms. Li and Atkins (2004) stated in their studies that there was a statistically significant relationship between the visual perceptions, sub-dimensions and conceptual skills.

It is believed that the increase that was not statistically significant the control group's post-test scores on the FDTVP test compared to the pre-test scores was related to the fact that the children are in a rapid growth model with the preschool educational programme implemented in the schools these children attend.

As in Table 1, which was reported earlier, prior to the implementation of the educational programme, the conceptual skills of the experimental and control groups were equal to each other; however, the educational sessions provided as part of the CEPBCM programme affected positively children's conceptual skills. In support of the hypotheses of this study, this education yielded more successful results compared to the traditional approach.

The implementation of the present educational programme, using the concept map, led children to perform significantly better on visual-spatial perception skills, as compared to the period before the implementation, and this helped them to be more successful on the test. This outcome indicates that concept maps are also effective for visual-spatial skills because not only are they easy, inexpensive, with direct instruction educational interventions but they are also active methods, which are more effective than other methods in displaying the conceptual relationships and connections and in forming cause and effect relationships.

The findings suggest that, as Table 2 shows, there was a significant difference between the pre- and post-test scores the experimental group obtained on the 'Perception of the place and location', 'Visual-motor coordination', 'Figureground perception', 'Figure stability' and 'Perception of the spatial relationships' sub-dimensions. The greatest difference among the scores obtained on the sub-dimensions of the FDTVP test was seen in the 'Perception of the place and location' sub-dimension, where the children had the highest score, all of the skills in the sub-dimension of the FDTVP 
test can be independently supported with the CEPBCM programme, and thus, the concept maps have the capacity of improving each subskill. Data in Table 3 indicate that there was a positive, significant relationship between all the subdimensions of the FDTVP and the experimental group's conceptual skills.

'Visual-motor coordination' requires cooperation between visual perception skills and physical development. Thus, the education provided with the concept maps is thought to significantly contribute to the development of visualmotor skills in various ways because it contains visual images that support the direction, shape or form, location or position concepts and visual perception. Marr, Windsor and Cemark (2011) implemented a concept skills education programme for children in their study and reported that children made progress in copying figures and letters, properly using the details that indicate the location of objects, and writing short and simple words. Similarly, Koc (2002) generated an educational programme model for developing visual perception skills and found that the experimental group in the study displayed a significant increase in visual-motor coordination, spatial relationships, figure stability, figure-ground perception and perception of the place and location dimensions, while the control group displayed no development.

Table 4 shows that there was a linear relationship between the correlation coefficients of both evaluation tools implemented for the experimental group. Moreover, a weak correlation, which was not statistically significant, was present between the subtests.

The findings reported by Klausmeier (1992), Vansledright and Frankes (2000) and Berti and Andriolo (2001) all of whom conducted similar studies on concept education revealed that the concept education strategy implemented for the experimental group generated positive, significant differences for learning concepts compared to the traditional education model.

Studies conducted by Manocha and Narang (2004) and Erden and Akman (2005), on concept development during early childhood, noted the importance of providing formal and configured concept education to children, suggesting that this education positively supported children in developing concepts.

Kabaca and Ozdemir (2002) reported in their studies that the concept map method significantly affected the memorisation skill and helped children to visualise information and activate the memory, and moreover, that it was an effective tool for learning insofar as it increased the rate of the interaction between the children and the rate of information exchange.

Table 5 indicates that there was a significant difference between the pre- and post-test scores of the experimental group, whereas there was no significant difference between the post- test and monitoring test, although there was a slight increase in favour of the monitoring test. The control group's pre- and post-test and permanence (monitoring) scores on the FDTVP and Boehm- 3 tests were found to be similar, with no significant difference found between the scores; although an increase was present on the permanence test compared to the post-test. These results suggest that the CEPBCM properly configured the children's concept and visual perception skills, based on their scores on concept skills, and this effect continued to be active after the education was completed. In the studies by Ratzon et al. (2009), which evaluated children's school-related skills and visual-motor coordination skills, it was reported that the children's success in the test for permanence (monitoring) in visual-motor coordination skills was consistent as a result of the education related to visual perception.

\section{Conclusion}

The differences found between the control and experiment groups in this study indicate that the concept education programme positively affected the experimental group in acquiring concepts and developing visual perception skills; that is, approximately a 30-point increase was seen in the mean conceptual skill scores of the children in the experimental group, the group in which the CEPBCM programme was implemented. In addition, a 12-point increase was observed in the mean visual-spatial perception skill scores, the results of which suggest that this education made a significant contribution to ensuring that the children acquire concepts and visual perception skills. Considering these findings and the characteristics of concept maps, concept maps are thought to be effective and efficient in helping children to improve their creativity-related skills for innovation, discovery and to gain conceptual information. Regarding the significant difference between the concept skill scores, it is fair to say that the CEPBCM programme is effective for certain functions of concept maps, such as materialising the learning process, understanding the concepts at the recognition and categorisation level and forming connections between the concepts.

Teachers should observe children's development in preschool educational programmes and prepare activities for developing visual-spatial perceptions. In this regard, curricula should be improved by using the concept maps.

\section{Implications and future perspective}

Contributions to educational programmes may be possible if the programme can be implemented after revisions are performed in the CEPBCM programme to determine and terminate the conceptual errors. Concept maps used in the field of education can be prepared in different types and formats, such as stimulants, boards and concept cycle.

For developing the children's visual concepts, parents should first properly understand their children's cognitive development process in the preschool period. Considering these data, it is important that parents be advised about activities based on concept maps to enable them to teach 
concepts in daily life. As a corollary to this, parents should be informed about different visuals based on concept maps, such as spider maps, flowcharts, chain of events and hierarchic boards, all of which can be prepared at home by taking examples from daily life.

It is recommended that other studies to be conducted in this field focus on comparing the findings by implementing the CEPBCM in different economic, social and cultural environments, and that programmes based on educational concept maps be prepared for other study group samples from Duzce to measure visual-spatial perceptions.

\section{Acknowledgements Competing interests}

The authors declare that they have no financial or personal relationships that may have inappropriately influenced them in writing this article.

\section{Authors' contributions}

Both the authors contributed to the conceptualisation, data collection and writing of the manuscript.

\section{Ethical considerations}

Ethics clearance has been granted by the Hacettepe Universitesi Ethical Committee for this research. The distribution of the children in both groups by their demographic characteristics is presented below. In the study, quite attention was paid to the parental consent form, and official permissions were obtained from the parents in accordance with the procedure. Ethical clearance number: 4311004.

\section{Funding information}

This research received no specific grant from any funding agency in any sectors.

\section{Data availability}

1. The data accessed in the programme of SPPS Statistical programme.

2. Appropriate art education pictures related to the application moment were taken and included in the article.

3. The limitations of the research are the 48-60-month-old children in the sample and the researchers who carried out the applications, the state of impartiality and environmental conditions.

\section{Disclaimer}

The views and opinions expressed in this article are those of the authors and do not necessarily reflect the official policy or position of any affiliated agency of the authors.

\section{References}

Berti, A.E. \& Andriolo, A., 2011, 'Third graders' understanding of core political concepts (law, nation-state, government) before and after teaching', Genetic, Social, and General Psychology Monographs 127(4), 346-377.

Boehm, A.E., 2001, Boehm preschool examiner's manual, The Psychological Corporation, Hartcourt Assesment Company, San Antonio.

Boisvert, K.A., 2003, An exploratory study of the development of the boehm test of basic concepts, 3rd edn., The University of Hong Kong Libraries, Hong Kong.

Cukur, D. \& Guller-Delice, E., 2011, 'Space design suitable for visual perception development in early childhood', Family and Society 7(24), 25-36.

Eddie-Gray, D.T., 2007, 'Abstraction as a natural process of mental compression', Mathematics Education Research Journal 2(19), 23-40. https://doi.org/10.1007/ BF03217454

Erden, M. \& Akman, Y., 2005, Development and learning, 14th edn., Friend Publishing, Ankara.

Ergul, A., 2007, 'Study of Boehm Pre-School Basic Concepts Test-3 adaptation for children aged 36-47 months', Master thesis, Ankara University, Ankara.

Erisli, S.D., Uluuysal, M. \& Dindar, B., 2013, 'Students' opinions on designing and interacting with an interactive teaching environment based on visual perception theories', Anadolu Journal of Educational Sciences International 3(1), 47-66.

Frank, M.C. \& Barner, D., 2012, 'Representing exact number visually using mental abacus', Journal of Experimental Psychology 141(1), 134-149. https://doi. org/10.1037/a0024427

Frostig, M., Lefever, D.W. \& Whittlesey, J.R.B., 1961, 'A developmental test of visual perception for evaluating normal and neurologically handicapped children',

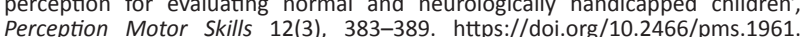
12.3.383

Genc, S., 2003, 'The development of visual perception skills of children aged five to six in terms of shape-ground perception', Journal of Vocational Education Faculty 5 , in terms 108.

Healey, J.M., 1997, Your child's developmental intelligence, transI. A.B. Dicleli, BZD Publishing, Istanbul.

Kabaca, T. \& Ozdemir, A.S., 2002, 'Use of concept map in secondary schoo mathematics education', Paper presented at the National Education of Science and Math Congress 16-18 October, ODTU, Ankara.

Karaahmet-Balcı, S., 2015, 'The requirement of visual culture education for creating aesthetic perception in art educational individuals', The Journal of Academic Social Science Studies 36, 465-477. https://doi.org/10.9761/JASSS2872

Klausmeier, H.J., 1992, 'Concept learning and concept teaching', Educational Psychologist 27(3), 267-286. https://doi.org/10.1207/s15326985ep2703_1

Koc, E., 2002, 'Preparing a sample program model for the development of visual perception skills and examining the effect of visual perception development on the children of the main class', Master thesis, Gazi University, Ankara.

Li, X. \& Atkins, M.S., 2004, 'Early childhood computer experience and cognitive and motor development', Pediatrics 113(6), 1715-1722. https://doi.org/10.1542/ peds.113.6.1715

Manocha, A. \& Narang, D., 2004, 'Concept development status of rural preschoolers', Journal of Human Ecology 16(2), 113-118. https://doi.org/10.1080/09709274.20 04.11905723

Marr, D., Windsor, M.M. \& Cemark, S., 2011, 'Handwriting readiness: Locatives and visuomotor skills in the kindergarten year', Early Childhood Research and Practice $3(1), 1-16$

Novak, J.D., 1990, 'Concept maps and Vee diagrams: Two metacognitive tools to facilitate meaningful learning', Instructional Science 19(1), 29-52. https://doi. org/10.1007/BF00377984

Novak, J.D., 1998, Learning, creating and using knowledge: Concept maps as facilitative tools in schools and corporations, Lawrence Erlbaum, Mahwah, NJ.

Ratzon, N.Z., Lahav, O., Hamsi, S.C., Metzger, Y., Efraim, D. \& Bart, O., 2009, 'Comparing different short-term service delivery methods of visual-motor treatment for first grade students in mainstream schools', Research in Developmental Disabilities 30(6), 1168-1176. https://doi.org/10.1016/j.ridd.2009.03.008

Sagol, U., 1998, 'The influence of Frostig visual perception program on visual perception of children with down syndrome', Master thesis, Marmara University, Istanbul.

Sokmen, S., 1994, 'Perceptional development on five aged children: Study of validity and reliability for Frostig Visual Perception Test', Master thesis, Marmara University, Istanbul.

Sucuoglu, B., Buyukozturk, S. \& Unsal, P., 2007, 'Validity and reliability studies of the Boehm Basic Concepts Test', Paper presented at the 4th National Language and Speech Disorders Congress, Istanbul.

Vansledright, B. \& Frankes, L., 2000, 'Concept- and strategic-knowledge development in historical study: A Comparative exploration in two fourth-grade classrooms', Cognition and Instruction 18(2), 239-283. https://doi.org/10.1207/S1532 690XCI1802_04

Wallace, J.D. \& Mintzes, J.J., 1990, 'The concept map as a research tool: Exploring conceptual change in biology', Journal of Research in Science Teaching 27(10), 1033-1052. https://doi.org/10.1002/tea.3660271010 